\title{
To Reason with Them or Tickle Them: Advertising Strategies in the Discourse of Persian Print Ads
}

\author{
Ida Reihani (Corresponding author) \\ English Language and Linguistics Department \\ Faculty of Foreign Languages, University of Isfahan, Isfahan, Iran \\ Tel: 0098-936-8840926 E-mail: ida.reihani@gmail.com
}

Abbas Eslami Rasekh (Ph.D.)

English Language and Linguistics Department

Faculty of Foreign Languages, University of Isfahan, Isfahan, Iran

Tel: 0098-311-7932110 E-mail: abbasseslamirasekh@yahoo.com

Received: 16-05- 2012

doi:10.7575/ijalel.v.1n.2p.185
Accepted: 20-06- 2012

Published: 01-07- 2012

URL: http://dx.doi.org/10.7575/ijalel.v.1n.2p.185

\begin{abstract}
Consumerism and the inevitable tracking of one's desired product among the endless rows and shelves of colorful products, highlights the importance of winning advertising strategies which have the power to persuade their audience to prefer one product over similar products. The present study aims to investigate two advertising strategies, reason versus tickle advertising and how they translate into the actual discourse of Persian print advertisements. To this end, a corpus of 150 ads was collected from two Iranian magazines, namely Honar-e Ashpazi and Zendegi-ye Ideal. Using the framework adopted by Simpson (2001) in telling apart reason vs. tickle ads based on their discourse features, Persian print ads were analyzed to identify which strategy is more prevalent. Furthermore, the nature of the advertised commodity (consumer's low-involvement or high-involvement) was observed to identify whether it is of any significance in the choice of the advertising strategy by the copywriter. The results demonstrated that the nature of the advertised product does not play a significant role in the strategy adopted by the copywriter and that Persian copywriters tend to employ a direct, factual approach in including the logical reasons why customers might prefer a certain commodity over similar ones in their advertising copy.
\end{abstract}

Keywords: Advertising (discourse), Reason advertising, Tickle advertising, CDA

\section{Introduction}

The growing consumerism in the present world and the endless colorful rows of diverse product types and services have not only managed to puzzle customers and clients all over the world but have also made manufactures and service providers seek more innovative ways to attract the attention of potential buyers for what they are offering. In other words, introducing one's products and services in an agreeable way to the potential customers has become a major staple for service providers and manufacturers. This emphasizes the importance of advertising which is a favorable representation of products to make consumers, customers and general public aware of the product. It is interesting to know what kind of marketing strategies and for what ideological, cultural purposes copywriters/advertisers employ in an advertisement in order to persuade people or provoke a certain reaction from the viewers.

Advertising, as a social institution that produces advertisements within a political economy of technical specialization, usually informs the public about a product or service via pictures, films, TV, newspapers, or the Internet, and it has become one of the most important forces in every society (Dyre, 1982).

There has been an enormous upsurge of interest in the linguistic and discourse characteristics of advertising over the last two decades. Introductory book-length treatments of the subject have tended to concentrate on the major levels of language organization in advertisements, including phonology, graphology, lexis and syntax

Page | 185 
International Journal of Applied Linguistics \& English Literature

ISSN 2200-3592 (Print), ISSN 2200-3452 (Online)

Vol. 1 No. 2; July 2012

(Vestergaard and Schroder, 1985; Cook, 1992; Myers, 1994). More specialist studies of advertising have highlighted, variously, its cognitive features (Pateman, 1983; Redfern, 1982; Harris, 1983), its cultural and anthropological dimensions (Aman, 1982; Goldman, 1992; Schmidt et al., 1994; O'Barr, 1994; Ohmann, 1996) and its status as a genre or register of discourse (Toolan, 1988). Working within the tradition of critical discourse analysis, other analysts have explored the political and ideological significance of advertising discourse (Williamson, 1978; Kress, 1987; Kress and van Leeuwen, 1990) and from this perspective special attention has been given to the representation of gender in ads (Goffman, 1976; Barthel, 1988; Thornborrow, 1994). Finally, given the interactive and dynamic properties of advertising, and the importance of contextual factors on the processing and interpreting of ads, it is not surprising that this type of discourse has been investigated within the parameters of models in linguistic pragmatics (Lakoff, 1982; Geis, 1982; Coleman, 1983, 1990; Tanaka, 1994; Short and $\mathrm{Hu}, 1997)$.

Writing as a professional copywriter and through the course of a generalized discussion about the strategies and goals of modern marketing, Bernstein (1974) draws a binary distinction between two principal copywriting strategies i.e. reason advertising and tickle advertising. Based on Bernstein's ideas, Simpson (2001) investigated not only these marking tactics, but also how these tactics are encoded into the discourse of advertising. His study was different from the previous ones in that they were pragmatic explorations of advertising discourse and tended to focus on the text-processing strategies taken up by the audience of advertisements (Reader/Viewer/Listener- RVL). His study changed the focus from the audience of the ads to the writers of those ads, the copywriters. Sifting through Bernstein's generalized discussion of marketing strategies, Simpson comes up with clear, more clean-cut definitions of Bernstein's binary distinctions drawn between reason and tickle advertising.

He defines reason advertising as an attempt to persuade the consumer by providing direct and easily decipherable reasons for the purchase. Tickle advertising, on the other hand, takes a more indirect approach by appealing to the humor, memories, and feelings of the potential customer. As he contends, while reason advertising emerges to be direct, factual and simple, tickle advertising seem to be indirect, more difficult to comprehend and in comparison with reason advertising, they need more active participation on the part of RVL to be understood.

On how reason-tickle distinction translates itself into the advertising texts, Simpson (2001) contends that 'reason' ads are characterized prototypically by:

1. Conspicuous product placement with brand name and (if available) company logo visually prominent,

2. A clear and unambiguous statement of the principal reason to buy the product.

No matter where they appear, whether in print or broadcast media, the basic discourse pattern of reason advertising remains stable. In print media ads, which are space-based, and which appear on the pages of newspapers and magazines or on billboards, reason ads normally are made of three basic components: 1 . The brand name, 2. A picture of the involved product, and 3. A sequence of written text which explains the reason to buy the product.

To pin down the discourse features of reason and tickle advertising in a real-world context, Simpson conducted a study on the corpus of British print and media ads which were either published or broadcasted in 1997 and adopted Halliday's systemic-functional framework, more specifically conjunctive adjuncts (1994) to come up with the underlying discourse structure of reason ads. These are:

(i) additive: and; also; moreover; nor.

(ii) adversative: but; yet; however; on the other hand.

(iii) conditional: [positive] if . . then; in the event of, when. [negative] otherwise; if not.

(iv) causal: so; then; because; as a result; that's why, ...

Which are put to use in the following advertisements. Note that the adjuncts are in bold:

(1) If he's wearing Pampers, he's staying dry.

(TV ad for 'Pampers Unisex Extra' nappies)

(2) Kotex understands how it feels to be a woman. That's why we've created new Kotex ultra-thin.

(TV ad for 'Kotex' sanitary towels)

Page | 186 
International Journal of Applied Linguistics \& English Literature

ISSN 2200-3592 (Print), ISSN 2200-3452 (Online)

Vol. 1 No. 2; July 2012

Though the underlying structure of both advertisements could be used to promote a wide range of other products and services, their propositional structure remains unchanged. It is easily comprehended by the audience and one can place and replace the two-place conditional with thousands and thousands of other conditional clauses and consequents to produce a large sum of easily-understood advertisements. The structure of reason-plus-result in the second ad also demonstrates another semantically well-formed structure which could be used to generate numerous instances of reason advertising.

Tickle advertising does not demonstrate the factual direct, easy-to-understand attributes of the reason advertising though on the surface they might display the structural features of reason advertising.

In her study of discourse features and marketing strategies in American magazine advertising, Kim (2007) investigated the role of two product type, namely snack foods and candies versus prescription medications in determining the type of language used in relevant print advertising. Drawing on Simpson (2001), she also studied the two prevalent discourse characteristics of reason advertising that is the use of conjunctive adjuncts and problem-solution information structure within print advertisements of two widely-read American magazines. Her results demonstrated a strong tendency for the use of conjunctive adjuncts in prescription medication advertisements and less use among the snack foods and candy advertisements. Since tickle advertising lends itself to more "indirect" strategies (such as implicature, humor and metaphor) and thereby is more difficult to describe or operationalize via discourse characteristics, Kim's paper fell short of dealing with it altogether.

While Simpson's criteria for identifying reason advertising through its marked discourse features seems adequate enough, identification of tickle advertising instances, subjective as it might be, calls for application of ideas and theories drawing from natural language philosophy. Hinted by Simpson but not thoroughly operationalized, Grice's (1975) maximal efficiency, which results from observing all four conversational maxims will produce flows of speech which tend to be direct, while the ostentatious flout of one or more maxims generates implicature which tend to be more oblique and take greater effort on the part of its audience to be processed and understood. It can be argued that maximal efficiency corresponds to reason advertising and implicatures signal tickle advertising. Schema 1 crudely depicts such correspondence:

\section{Schema 1}

$\begin{array}{lll}\text { Reason } & \text { Direct } & \text { Maximal efficiency } \\ \text { Tickle } & \text { Oblique } & \text { Implicature }\end{array}$

In this study efforts will be made in order to identify the discourse features of the two major advertising strategies, reason versus tickle advertising techniques as employed in the Iranian print ads in magazines. More specifically, the aim is to identify the cultural influences which function to make advertising cross-culturally different.

Furthermore, it will be determined whether these advertising strategies translate themselves into the advertising discourse of Iranian print ads the same way they do in English. To this end, Simpson's criteria for identifying reason and tickle ads (2001) will be put into use.

The present research will address the following questions:

1. What are the discourse features of 'reason' versus 'tickle' advertising in print ads in Iranian magazines?

2. Are there any significant differences between the discourse features of 'reason' advertising in British English print ads and Iranian print ads?

3. Does the nature of the advertised commodity affect the choice of the advertising strategy by the copywriter?

To answer the question of whether Iranian copywriters make use of the same or different text-building devices than those of their British counterparts (Simpson, 2001), within the structure of reason ads, the particular linguistic devices which expound Halliday's textual metafunction (Halliday, 1994:36) and he terms "conjunctive adjuncts" will be investigated.

Last but not least, drawing upon the distinction between consumer low- and high-involvement goods (Mueller, 1992), the type of advertising strategy in two product categories, home appliances versus cheap packaged food products and health products which represent high- and low-involvement goods, respectively, is investigated in the context of Persian print ads to figure out the prevalent strategy type in terms of their frequency within the aforementioned categories.

Page | 187 
International Journal of Applied Linguistics \& English Literature

ISSN 2200-3592 (Print), ISSN 2200-3452 (Online)

Vol. 1 No. 2; July 2012

\section{Method}

Simpson's (2001) model for categorizing reason versus tickle ads was employed. Being a blended approach, it makes use of Bernstein's (1978) typology of reason and tickle ads and incorporates several pragmatic models of how reason and tickle advertising strategies actually translates into the discourse of ads.

In dealing with the discourse features of reason ads, Simpson (2001) refers to a set of text-building devices which he deemed especially illuminating when applied to reason ads. Conjuctive adjuncts, first introduced by Halliday's (1994) Systemic Functional Grammar (SFG) proved to be an essential part within the copy of English print reason ads. Persian print ads were then analyzed against the scopes of Simpson's (ibid.) framework to identify similar agendas to that of British print ads. Tickle ads, on the other hand, could not be investigated against a set or sets of text-building devices but were rather identified according to their use of implicatures in their structure.

Finally, the nature of the involved commodity, being either consumer's low or high involvement (Meuller, 1992) was taken into account to find out whether it influences the advertising strategy chosen by the copywriter

\subsection{Advertising Data}

A total of 150 advertisements from two Persian magazines (Honar-e Ashpazi and Zendegi-ye Ideal) were collected from March 2010 to march 2011. Those used in the descriptive analysis within the present study had to meet certain criteria, i.e. they had to roughly at least fall within the category of low-price packaged foods, or home appliances. The reason for the specific choice of these two groups of commodities is that their certain characteristics matched those of consumer's low and high involvement. All selected advertisements publicize products rather than services.

Since both Honar-e Ashpazi and Zendegi-ye Ideal are two popular mainstream magazines, and they are available in most newsagents in Iran, they are ideal for the purposes of this study.

\subsection{Design of the Study}

In order to give a clear image of how copywriters generally handle the presentation of a commodity in a print advertisement (being either more of a reason or tickle ad), it was deemed important to firstly present the general layout of a print advertisement. 1. The visual elements of the ad, 2. The headline which is usually the second content the reader sees to understand what it is the ad is conveying to its reader. Headlines are usually clever, smart, funny and to the point. Sometimes a headline is not needed if the visual strongly communicates the message. 3. A central visual is used to tie in the headline. We need to know what it is the company is communicating. 4. The company's logo. We need to know who is selling the product or service. 5. Support body copy. In many cases this varies. Some ads have it and some have very little. One line usually required, is the pay-off to allow the reader to make action. It is the structure of the verbal text that is the copy in print ads which will receive closest scrutiny in the analysis.

In addition to Simpson's (2001) blended approach to distinguishing reason and tickle advertising, it was deemed appropriate to consolidate Grice's (1975) maximal efficiency in the case of reason advertising and the deliberate flouting of the maxims in the case of tickle advertising. To this end, the advertising copy was subjected to process of the identification of either the maxims or flouting of them for that matter. A descriptive and detailed approach in dealing with the advertising copy helped identify recurring schemes within Persian print advertisements. That would prove fruitful in drawing the final comparisons between the uses of advertising strategies in English and Persian print advertisements.

\section{Results and Conclusion}

In the case of both home appliances and cheap packaged foods, the description aims to provide a vivid outline of the visuals and how the headline and copy are incorporated into the ad's layout. Interestingly, similar trends were observed in both categories. In case of both home appliances and low-priced packaged foods and health products, copywriters tended to incorporate a list of features/benefits of the product along with the implied but not overtly stated:

(a) two-place conditional: If you buy product $X$, you will enjoy features/benefits such as (blank)

(b)reason-plus-result statement: You should buy product $\mathrm{X}$ because (blank)

Since the two patterns could be filled in with many possible features/benefits, these two general formats yield numerous instances of print ads which might be different in layout or visuals, but have the same underlying discourse structure.

Page | 188 
International Journal of Applied Linguistics \& English Literature

ISSN 2200-3592 (Print), ISSN 2200-3452 (Online)

Vol. 1 No. 2; July 2012

Out of the 53 advertisements showcasing home appliances and gym equipments 37 ads made use of reason advertising. In order to facilitate the flow of discussion, a number of ads will be presented along with the possible considerations which might have been influential in shaping their A good example would be that of Rainsport $^{\mathrm{TM}}$ home gym equipments (Honar-e Ashpazi, issue No.67, April 2009):

1. [context] (Appendix 1)

The central visual of this print ad features the modern treadmill (running machine) located in a partly modern household environment, traditional elements including a traditional Iranian burning lamp and a fishbowl with two gold fishes are also incorporated into the artwork.

The copy reads:

- $\quad$ Teredmil emkān-e varzesh va salāmati rā dar khāne farāham mi-āvarad, pas bā teredmil be tanāsob-e andām beresid.

- $\quad$ Treadmill provides you the possibility of exercising at home, so become fit with treadmill.

The conjunctive adjunct 'Pas' in Persian equivalent to 'So' in English signals the causal, reason-plus-result structure. Conspicuous product placement (hereby referred to as CPP) along with the statement of the principal reason to buy the product in the headline, professional home-exercising and fitness made possible with the home gym equipment makes for a reason advertisement. The luxurious nature of the involved commodity hints at a consumer high-involvement good which not all can afford, since thought and money must be put into buying a home gym device not everyone may see as necessary in the household. Other examples of print advertisements including a primary reason for the purchase of an advertised home appliance are as follows:

2. ParsKhazar Tea Brewer (Honar-e Ashpazi, issue No.71, September 2009)

[context]

The central visual of the ad incorporates an image of the product (CPP) along with the primary reason for the purchase of the product. It is one of those instances in which all aspects of the ad make for a reason ad. Not only is the product conspicuously placed, the main reason for the purchase is offered as the answer to a question the ad posits for its potential customers:

- Cherā damāvar-e pārskhazar motefāvet ast? [Zirā] bā...

- Why is ParsKhazar tea brewer different? Because...

Persian print ads advertising low-priced packaged foods and cheap health products made use of equal instances of reason and tickle advertising. The following example in its minimalistic approach could be a perfect tickle ad for low-priced packaged food, in this case dry pasta, (Honar-e Ashpazi, issue No.70, July 2009)

\section{MAK Pasta}

[context] (Appendix 2)

The visual of this beautiful minimalistic advertisement presents only a bunch of fresh tomatoes, a couple of garlic cloves and some blurred wheat spikes on the upper half of the page. A bunch of spaghetti strings are also in the view as they protrude from among the pile of vegetables (CPP). No copy is provided; the brands slogan is presented along its logo on the bottom half.

- $\quad$ Ghazā-ye khūb, ehsās-e khūb

- $\quad$ Good food, good feeling

In its minimalistic presentation, and in its lack of any advertising copy, one can find the main appeal of the advertisement. By flouting the maxim of quantity that is by saying less than what is needed to be said.

The audience of ad will however have no problem to perceive the message of the advertisement, i.e. 1. People favor good foods over bad foods, 2. People will likely feel better, fuller and more content if they eat good food, 3 . MAK $^{\mathrm{TM}}$ pasta will make for a good food, 4. If people want to feel better after having a dish, they should choose MAK ${ }^{\mathrm{TM}}$ pasta.

Page | 189 


\section{International Journal of Applied Linguistics \& English Literature}

ISSN 2200-3592 (Print), ISSN 2200-3452 (Online)

Vol. 1 No. 2; July 2012

As suggested for tickle ads for general, and as they engage more active process on the part of the potential buyer, the present ad, too, can be considered more of a tickle than a reason ad.

\section{Borjomi Naturally Carbonated Mineral Water [Honar-e Ashpazi magazine, No. 74, November 2010]}

[context] (Appendix 3)

In what could be regarded as a perfect instance of tickle advertising, the visual consists only of the number "120" against a white background and the word "Borjomi" written below. No copy or headline neither a single shot of the product is provided.

What is interesting is how the ad ignites the curiosity in the mind of the reader. Several questions may pop in his head:

What is the advertised product?

- What does Borjomi mean?

$\circ \quad$ What is the significance of the number "120"?

As Bernstein (1974) had pointed out: "If everything is spelled out, the only reaction may be indifference. But if people are intrigued, and comprehension is not immediate, they may go on to participate in the advertising."

In the later issue of the same magazine, the ad was reprinted but in an interesting addition, the words "years" and "since 1980" were added to the original ad. In the reprinted version, the ad answers the question about the significance of number "120", clearly referring to a span of one hundred and twenty years of experience. The ad cleverly refrains from providing further information.

The ad's subsequent reprint (with more info) seems to have been a calculated strategy to appeal to the playful side of the reader and engage his curiosity and jumpstart his search for more information. Moreover, the ad obviously chooses to say less (actually much less) than needed and remains ambiguous throughout. Not only in its layout but also in the fact that it flouts the maxims of quantity and relevance, it could be regarded as a prototype of tickle advertising. (Borjomi is actually a brand of naturally carbonated mineral water from springs in the Borjomi Gorge of central Georgia which recently has become available in the Iranian market.)

It is worthy of mention that no ad is strictly reason or tickle. In the case of home appliances such as washing machines, dishwashers, home gym equipments which were rather expensive or luxurious for the large number of members in the destined audience, it was not surprising to find out that reason advertising was the more prevalent advertising strategy, signifying that people need more persuasion, in this case more logical reasons in order to be talked into buying something expensive and when the range of choices are relatively small. Table 1 and table 2 summarize the findings for both product categories:

Table 1. Number of advertising strategies along with product categories

\begin{tabular}{llll}
\hline & Reason advertising & Tickle advertising & Total \\
\hline Home appliances & 37 & 16 & 53 \\
$\begin{array}{l}\text { Packaged foods and } \\
\text { health products }\end{array}$ & 48 & 49 & 97 \\
Total & 85 & 65 & 150 \\
\hline
\end{tabular}

Table 2. Percentage of advertising strategies along with product categories

\begin{tabular}{lll}
\hline & Reason advertising & Tickle advertising \\
\hline Home appliances & $70 \%$ & $30 \%$ \\
$\begin{array}{l}\text { Packaged foods and } \\
\text { health products }\end{array}$ & $49 \%$ & $51 \%$ \\
\hline
\end{tabular}


International Journal of Applied Linguistics \& English Literature

ISSN 2200-3592 (Print), ISSN 2200-3452 (Online)

Vol. 1 No. 2; July 2012

Based on the criteria established for recognizing reason and tickle advertising, reason advertising instances are clear, direct and logical which in turn highlights the non-existence of implicatures, i.e. instances of the flouting of maxims while on the other hand, tickle advertising tends toward the more oblique, the understanding of which calls for more active engagement on the part of the audience of the ad.

The large number of the application of reason advertising strategy to feature high-involvement commodities is quite interesting. This seems to be in keeping with Kim's (2007) findings that high-involvement products often lend themselves to reason-oriented strategy in advertising which offer obvious and rational benefits to their customers. Though tickle advertising is scarcely used to feature high-involvement products, the very few instances may indeed provide interesting insights into the ideological, cultural considerations on the part of the Persian copywriters. One interesting case was that of Bosch ${ }^{\mathrm{TM}}$ home appliances:

\section{Bosch Home Appliances [Honar-e Ashpazi magazine, No. 7o, August 2010] \\ [context] (Appendix 4)}

In keeping with the spirit of Ramadan, this one-page print advertisement cleverly makes use of tokens associated with the Holy Month. Here, a crescent-shaped green leaf appearing atop an immensely green planet reinforces the advertised green nature-loving earth-friendly nature of the Bosch ${ }^{\mathrm{TM}}$ products. The headline reads:

- $\quad$ Ramezān-e emsāl, zamin rā niz mote'āli konim. (Honar-e Ashpazi, issue No. 67, July 2010)

- $\quad$ This Ramadan, sublimate the earth as well.

suggesting, along with the sublimation of one's self with prayer, good deeds and fasting and divine illumination during Ramadan, the earth can be a better, cleaner, and greener place if one purchases and uses Bosch ${ }^{\mathrm{TM}}$ home appliances.

The copywriter knows that the ad's audience is largely made up of Iranian Muslims who respect the spirit of Ramadan and thus, he succeeds in attributing a favorable spiritual image to the advertised commodity. On the surface, the ad clearly flouts the maxim of relevance by expressing an advertising message completely irrelevant to the matter at hand; all the while it is successful in grabbing the attention of its destined audience. On another level, the ad persuades, one can say even manipulates its audience into buying the product using its religious undertones.

To find out whether Persian reason ads and the English ones employ different discourse features, it was deemed appropriate to compare the two based on their use of conjunctive adjuncts to see whether Simpson's (2001) rule could be generalized from the realm of British-English advertising to Persian advertising. This in turn yielded interesting results. While Kim's (2007) study of print advertisements in Better Homes and Gardens and National Geography was indeed supportive of Simpson's proposed typology, in that reason advertising makes use of conjunctive adjuncts to showcase the reasons to buy, Persian reason advertising instances tend to make use of the additive 'and' only to put together reasons why customers should prefer a certain merchandise.

While the scope of the study was rather limited, its implications however, could prove beneficial to be incorporated into related study fields. First, the study directly addressed the issue of using two mainstream advertising strategies, namely reason and tickle in English and Persian print ads' copies as employed and incorporated into their discourse by English and Persian copywriters.

The implications and applications of the results of present research are three-fold. While firstly and most importantly, the findings could be fruitful to those seeking fresh insights into cross-cultural communication aspects, the results could also prove enlightening for those working in the area of English for Specific or Business Purposes who seek to provide authentic materials for junior or professional copywriters working in both in Iran and overseas. Translators might also benefit from the findings, as they illustrate how cultural factors influence the way advertising slogans, texts, etc. are translated into one's own language. Copywriters themselves, Persian or English, may benefit from the results of the study by seeing how their counterparts may vary their use of advertising strategies based on the commodity involved and more importantly the culture of the potential buyers.

Some limitations in this study warrant attention. First, the limited size of the advertising sample along with the lack of precedent in the methodology in carefully analyzing advertising strategies and their discourse features all dictate caution both in interpretation and generalization of the findings. As a result of an effort to maintain the Page | 191 
International Journal of Applied Linguistics \& English Literature

ISSN 2200-3592 (Print), ISSN 2200-3452 (Online)

Vol. 1 No. 2; July 2012

standards of a relatively comprehensive study in conjunction with thesis length restrictions has left our treatment of the advertising strategies rather brief. Finally, any analysis of advertisements presents manifold challenges due to their ability to draw upon various genres simultaneously to convey their messages through a combination of verbal and nonverbal signs for print ads.

While the design of the present study was essentially a descriptive one in dealing with the print ads, it might be crucial to any further research to make use of experimental designs that differ from those conventionally used with print ads. The same design however, could be aimed at comparing and contrasting reason and tickle advertising strategies and their exclusive discourse features in any two languages and the focus of the study might move from print advertisements or space-based ads on the billboards to media ads broadcasted on TV and radio. To consider a more purely cultural interpretation used in this study could be another useful perspective in future research. Another area for further research would be to replicate this study in other cultural contexts in order to gain understanding of the role of culture in the use advertising strategies by the copywriters. As this study was carried out only on verbal parts of the ads, the most interesting extensions of research may come from examining verbal materials along with the visual components of ads. Another interesting twist may come from considering other commodity categories and how the unique nature of the product might influence the advertising strategy and relevant linguistic features.

\section{References}

Aman, R. (1982). Interlingual taboos in advertising: How not to name your product. In R.J. Di Pietro, (Ed.), Language and the professions (215-224). Norwood, NJ: Ablex.

Barthel, D. (1988). Putting on appearances: Gender and advertising. Philadelphia, PA: Temple University Press. Bernstein, D. (1974). Creative Advertising. London: Longman.

Coleman, L. (1983). Semantic and prosodic manipulation in advertising. In R. J. Harris (Ed.), Information-processing research in advertising. Hillsdale NJ: Erlbaum.

Cook, G. (1992). The discourse of advertising ( $2^{\text {nd }}$ ed.). London and New York: Routledge.

Dyre, G. (1982). Advertising as communication. London: Routledge.

Geis, M. L. (1982). The language of television advertising. New York: Academic Press.

Goffman, E. (1976). Gender advertisements. Cambridge, MA: Harvard University Press.

Goldman, R. (1992). Reading ads socially. London: Routledge.

Grice, H. Paul, 1975. Logic and conversation. In: J. Cole and .I. Morgan, eds., Speech acts (Syntax and semantics 3). 41-58. New York: Academic Press.

Halliday, M. A. K. (1994). An introduction to functional Grammar (2nd Ed.). London: Arnold.

Harris, R. J. (Ed.). (1983). Information processing research in advertising. Hillsdale, NJ: Erlbaum.

Kim, M. (2007). Discourse features and marketing strategy in American magazine advertising. Texas Linguistic Forum 51: 95-102.

Kress, G. (1987). Educating readers: Language in advertising. In J. Hawthorn, (ed.), Propaganda, persuasion and polemic (123-139). London: Arnold.

Kress, G., \& van Leeuwen, T. (1990). Reading images. Deakin, Victoria, Australia: Deakin University Press.

Lakoff, R. T. (1982). Persuasive discourse and ordinary conversation, with examples from advertising. In D. Tannen (Ed.), Analyzing discourse: Text and talk (25-42). Washington, DC: Georgetown University Press.

Mueller, B. (1992). Standardization vs. specialization: An examination of westernization in Japanese advertising. Journal of Advertising Research, 32, 15-24.

Myers, G. (1994). Words in ads. London: Arnold.

O'Barr, W. (1994). Culture and the ad: Exploring otherness in the world of advertising. Boulder, CO: Westview. Ohmann, R. (1996). Selling culture: Magazines, markets, and class at the turn of the century. London: Verso.

Pateman, T. (1983). How is understanding an advertisement possible? In H. Davis \& P. Walton (Eds.), Language image media (187-204). Oxford: Blackwell.

Page $\mid 192$ 


\section{International Journal of Applied Linguistics \& English Literature}

ISSN 2200-3592 (Print), ISSN 2200-3452 (Online)

Vol. 1 No. 2; July 2012

Ptashchenko, N. (2008). Headline as a persuasive tool in publicistic discourse, Munich, GRIN Publishing $\mathrm{GmbH}$.

Redfem, W. (1982). Guano of the mind: Puns in advertising. Language and Communication, 2: 269-276.

Schmidt, R., Shimura A., Wang Z., \& Jeong, H. (1994). Suggestions to buy: Television commercials from the US., Japan, China and Korea. In S. Gass \& J. Neu, (Eds.), Speech acts across cultures (285-316). Berlin: Mouton de Gruyter.

Short, M., \& Hu, W. (1997). Analysing the changing character and sophistication of TV advertisements in the People's Republic of China. Text, 17: 491-515.

Simpson, P. (2001). "Reason" and "tickle" as pragmatic constructs in the discourse of advertising. Journal of Pragmatics, 33, 589-607.

Tanaka, K. (1996). Advertising language: A pragmatic approach to advertisements in Britain and Japan. New York: Routledge.

Thornborrow, J. (1994). The woman, the man and the filofax: Gender positions in advertising. In S. Mills, (Ed.), Gendering the reader (128-151). Hemel Hempstead: Harvester Wheatsheaf.

Toolan, M. (1988). The language of press advertising. In M. Ghadessey, (ed.), Registers of written English (52-64). London: Pinter.

Vestergaard, T., \& Schroder, K. (1985). The language of advertising. Oxford: B. Blackwell.

Williamson, J. (1978). Decoding advertisements: Ideology and meaning in advertising. London: Boyars.

Honar-e Ashpazi magazine, April, 2009

Honar-e Ashpazi magazine, July, 2009

Honar-e Ashpazi magazine, July, 2010 


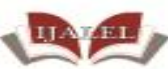

International Journal of Applied Linguistics \& English Literature ISSN 2200-3592 (Print), ISSN 2200-3452 (Online)

Vol. 1 No. 2; July 2012

Appendix1. Advertisement of 'Rainsport' treadmill extracted from 'Honar-e Ashpazi' magazine (2009)

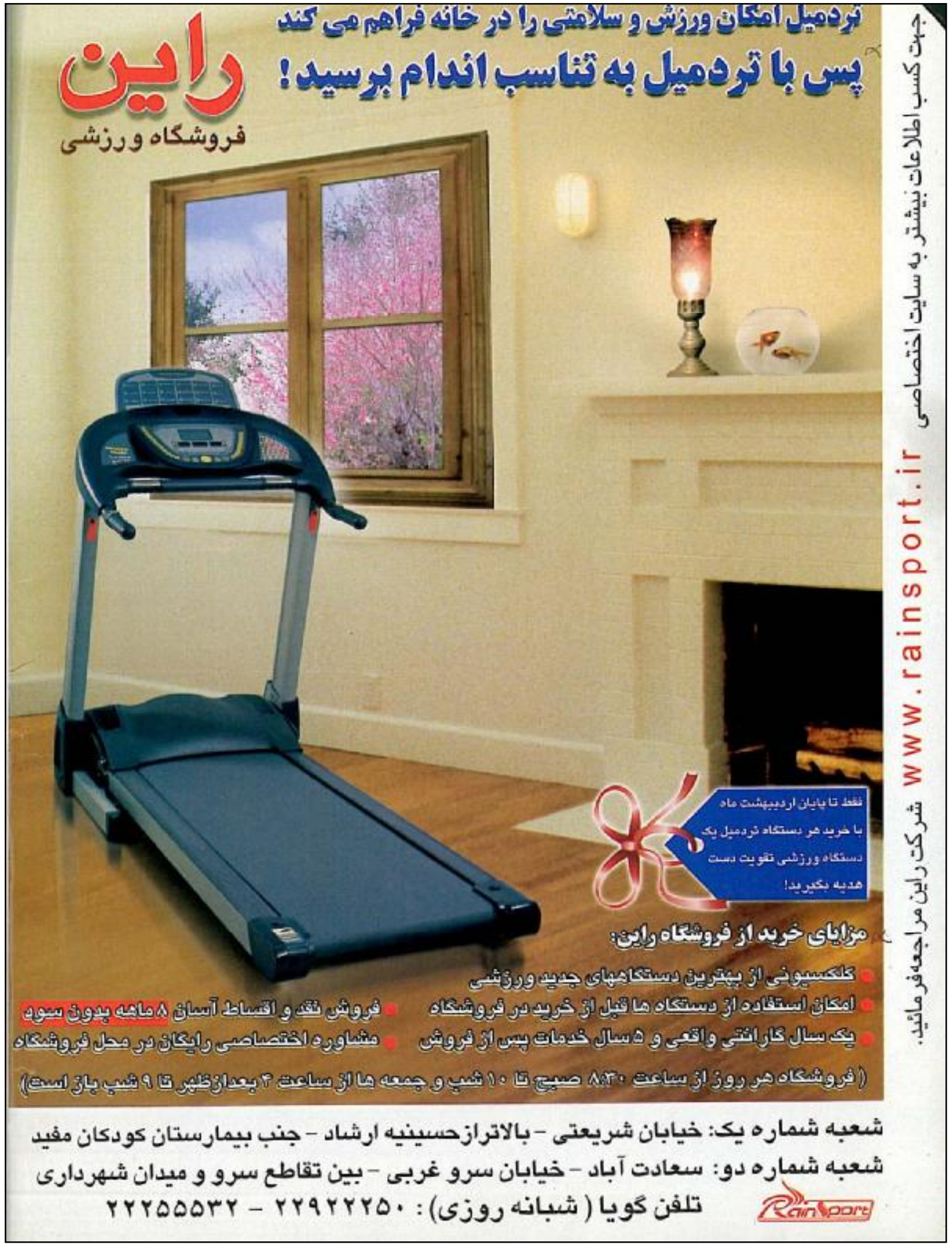




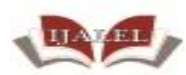

International Journal of Applied Linguistics \& English Literature ISSN 2200-3592 (Print), ISSN 2200-3452 (Online)

Vol. 1 No. 2; July 2012

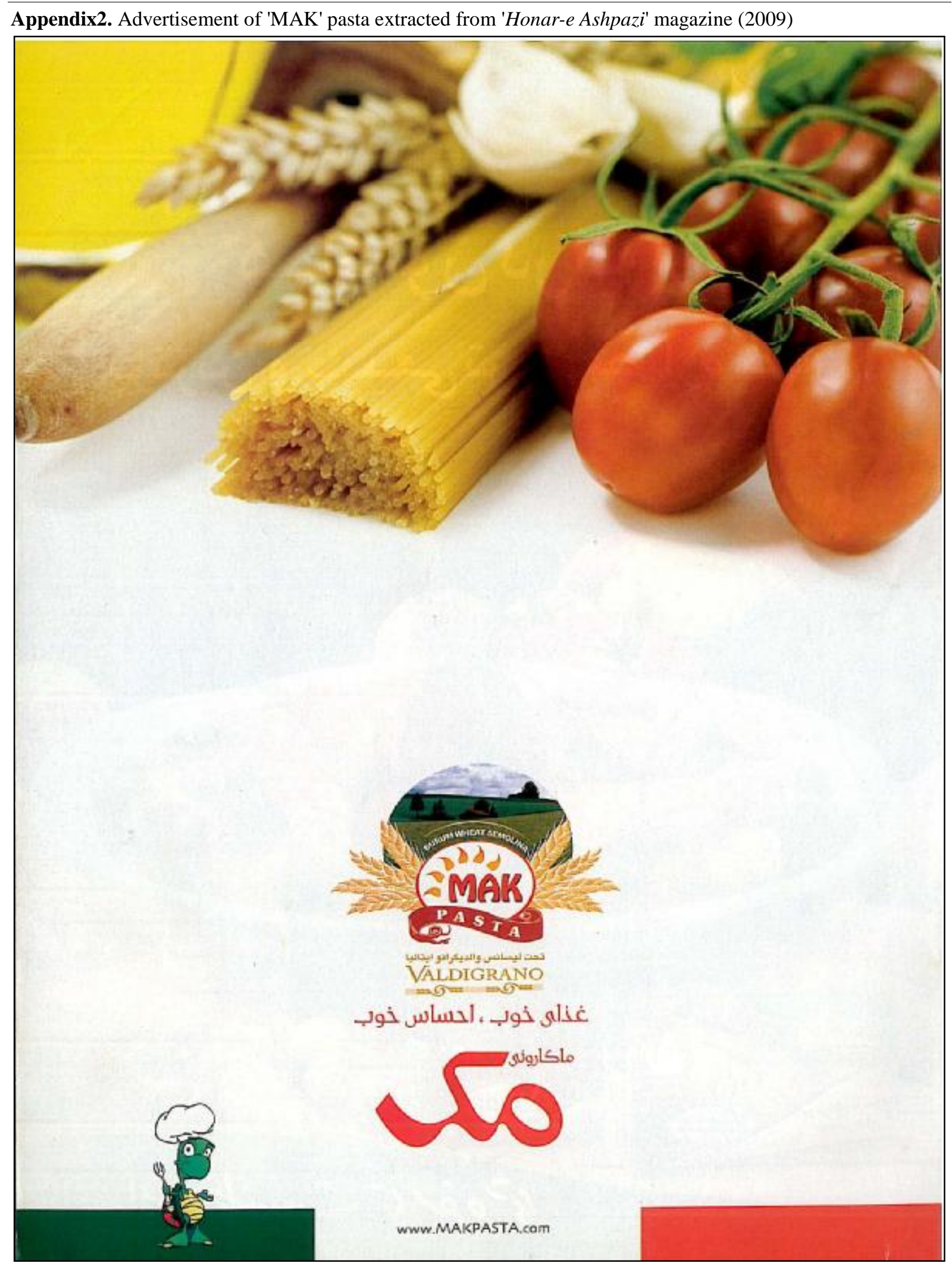


International Journal of Applied Linguistics \& English Literature ISSN 2200-3592 (Print), ISSN 2200-3452 (Online)

Vol. 1 No. 2; July 2012

Appendix3. Advertisements of 'Borjomi' mineral water extracted from 'Honar-e Ashpazi' magazine (2010)
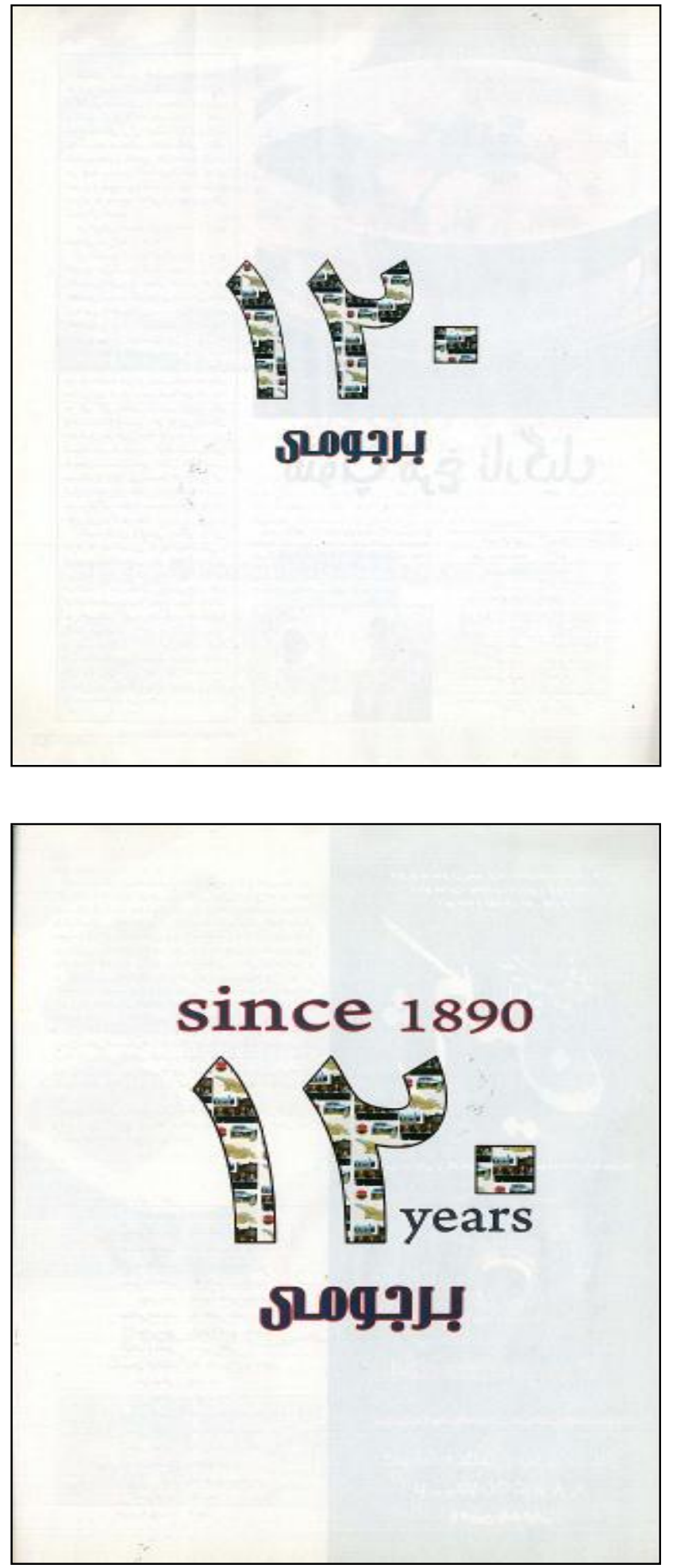

Page | 196 


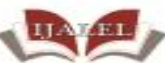

International Journal of Applied Linguistics \& English Literature ISSN 2200-3592 (Print), ISSN 2200-3452 (Online)

Vol. 1 No. 2; July 2012

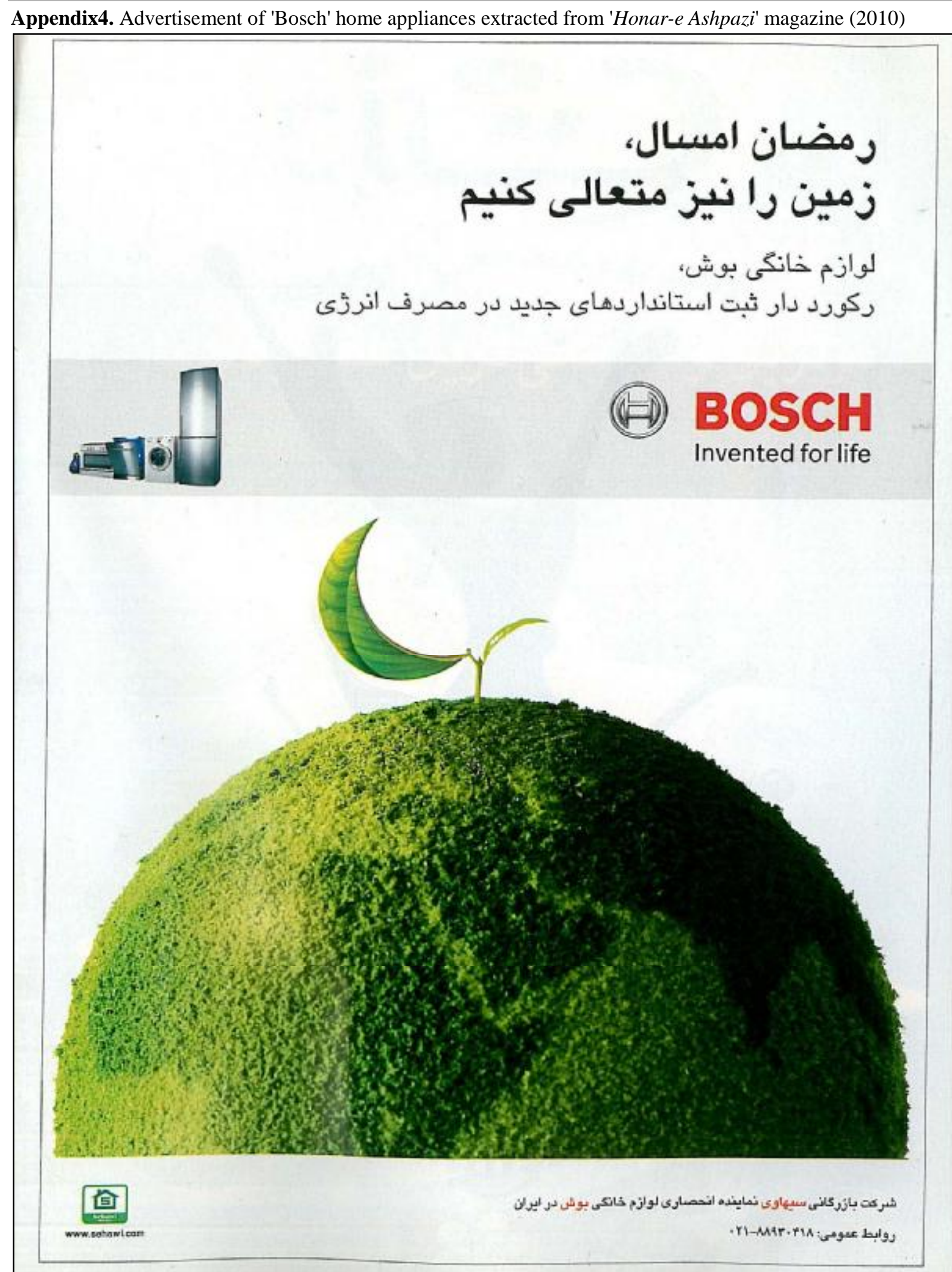

